\title{
Hydro Scheduling Optimization Considering the Impact on Market Prices and Head Drop Using the linprog Function of MATLAB ${ }^{\circledR}$
}

\author{
M. Silva e Castro, J. C. Sousa \\ Faculty of Engineering of University of Porto, Portugal \\ Rua Dr. Roberto Frias, 4200-465 Porto, Portugal \\ ee11198@fe.up.pt Jose.Sousa@fe.up.pt
}

\author{
J. T. Saraiva, Member, IEEE \\ INESC TEC and Faculty of Engineering of University of \\ Porto, Portugal \\ Rua Dr. Roberto Frias, 4200-465 Porto, Portugal \\ jsaraiva@fe.up.pt
}

\begin{abstract}
This paper describes an enhanced model for the Short Term Hydro Scheduling Problem, HSP, that includes the impact of operation decisions on the market prices and the possibility of adjusting the tailwater level and the generation and pumping efficiencies as a function of the flow. The solution approach uses an iterative procedure that solves in each iteration a linearized HSP problem using the linprog function of the MATLAB ${ }^{\circledR}$ Optimization Toolbox and that updates the value of the head to be used in the next iteration. The paper also includes results from a realistic Case Study based on the cascade of 9 hydro stations ( 4 of them with pumping) installed in the Portuguese section of the Douro River.
\end{abstract}

Index Terms-- Short-Term Hydro Scheduling, hydro units, optimization, electricity markets.

\section{INTRODUCTION}

The evolution of the electricity sector originated structural changes in the way the electricity business is developed. The sector moved from a monopolistic and centralized view to a disaggregated and decentralized logic. Electricity transactions are now made in a highly competitive environment, subject to market rules. The introduction of competition in activities as generation and retailing justifies the development of new models and tools to ensure that the most adequate decisions are adopted $[1,2]$. In this scope, to gain advantage over other agents, generation companies develop and adopt optimization models to adequately plan the use of their assets. On the other hand, the Portuguese trade balance is heavily penalized by the import of hydrocarbon fuels. Accordingly, the construction of new hydro plants and the repowering of the existing units is a key issue to ensure a more sustainable future and to improve the Portuguese energetic independence.

Planning problems, particularly in energy systems, often have non-linear objective functions. Existing limitations established due to legal or technical requirements have nonlinear characteristics in most cases. Some published papers mention the successful application of non-linear techniques to solve the Short-Term Hydro Scheduling Problem, STHSP [3], [4]. However, the effect of dimensionality occurs here, because as the size and complexity of the problem augments, these techniques become very computational heavy.

Regarding the operation of hydroelectric power plants, several publications use evolutionary and genetic techniques that are reported to provide acceptable solution times as in [5]-[8]. One of biggest drawbacks associated to the application of meta-heuristics to the HSP is the difficulty in introducing new operational constraints as mentioned in [9].

Dynamic programming is able to deal with the non-linear and non-convex characteristics of the HSP. However, the major disadvantage of this technique resides in the "curse of dimensionality" which means that for problems with many states becomes increasingly difficult [10]. An example of the difficulty in applying this technique is the operational optimization of hydro stations addressed in this paper, in which many periods and units are considered. It should also be noted that, for cascaded systems, the processing times and the required memory grow exponentially with the size of the problem as indicated in [11].

Previous attempts to implement a stochastic programming algorithm to the multi-reservoir HSP indicated that there was an unprecedented growth in the number of states, rendering the resolution impractical [11] because prices and inflows also had to be considered as states. The complexity of the HSP problem is increased when including the hydraulic interconnections between units in the same basin as well as the pumping capacity of some units. The non-linear relationship between the head, the flow and power output also requires using a large computational effort, specially for real sized systems [12]. Altogether, this means that the computational requirements associated with this optimization problem rapidly increases as the planning horizon gets larger and the number of plants is increased.

In the computer application reported in this paper we adopted an iterative approach to solve the original non-linear HSP problem in which the value of the net head is assumed fixed in each iteration. When an iteration ends, the net head is recomputed and an updated value is then used in the next iteration. The developed model includes the possibility of pumping to increase the realism and applicability of the developed application as well as the impact of the operation decisions on the markets prices. In this sense, the procedure starts with an initial set of prices that are used to obtain an initial set of generation or pumping decisions for the units. Using these decisions for each hour of the horizon, the market curves provided as input are updated so that a new set of 
prices are obtained. As a result, the benefit of the operation of the hydro units is estimated in a more realistic way, because market prices tend to increase when pumping exceeds generation and tend to reduce if generation exceeds pumping.

This work was developed in the scope of the MSc thesis submitted by the first author to the Faculty of Engineering of Universidade do Porto in June 2016 and it was prepared with the collaboration of EDP Gestão da Produção SA. Apart from this Introduction, Section II details the mathematical formulation of the HSP problem and Section III describes the developed solution approach. Section IV presents the results that were obtained using the mentioned Case Study and Section V includes the most relevant conclusions.

\section{MATHEMATICAL FoRMULATION OF THE HSP PROBLEM}

The Hydro Scheduling Problem (HSP) is an optimization problem to schedule a number of hydro units and it can be established for different time horizons. In our case, we are addressing a short-term problem to define a schedule for each unit in terms of having an operation decision as a generator or as a pump or eventually having the unit stopped and typically considering a period of 1 day to 1 week, discretized in periods of 1 hour. In several countries, the hourly generation schedules are set in centralized electricity markets to which generation companies have to submit their selling bids (hydro stations operating as generators) or buying bids (hydro stations operating as pumps). In this case, it is crucial that generation companies submit the most adequate bids as a way to maximize their revenues. To do that they can run simulation models as the HSP in order to identify the most adequate operation strategies which justifies the relevance gained by this problem in recent years.

For an hydro unit $\mathrm{i}$ in hour $\mathrm{k}$, the generated power is given by (1) considering the losses in the hydro circuit. The density of the water is approximately equal to $1000 \mathrm{~kg} / \mathrm{m}^{3}$ and the gravitational acceleration is given by $\mathrm{g}=9.8 \mathrm{~m} / \mathrm{s}^{2}$. The power required to pump a flow $q_{i k}$ is given by (2).

$$
\begin{aligned}
& P_{G i k}=9.8 \times q_{i k} \times\left(h_{i k}-\beta \times q_{i k}^{2}\right) \times \eta_{G} \\
& P_{P i k}=9.8 \times q_{i k} \times\left(h_{i k}+\beta \times q_{i k}^{2}\right) / \mu_{P}
\end{aligned}
$$

In these equations:

$q_{i k}$ - discharged/pumped water flow in $\mathrm{m}^{3} / \mathrm{s}$;

$h_{i k}$ - gross head in meters;

$\eta_{G}$ and $\mu_{P}$ - generation and pumping efficiencies;

$\beta$ - head loss coefficient.

The head loss coefficient is given by (3) and it depends on the nominal head loss $\Delta h n$ and on the nominal discharge flow $q n$. Once the head loss coefficient is calculated, expression (1) indicates that there is a non linear dependency between the power, the discharge flow and the head because of the $\beta \times q_{i k}^{2}$ term as illustrated by the blue curve in Fig. 1. This term can be seen as a reduction of the head and it depends on the flow.

$$
\beta=\frac{\Delta h n}{q n^{2}}
$$

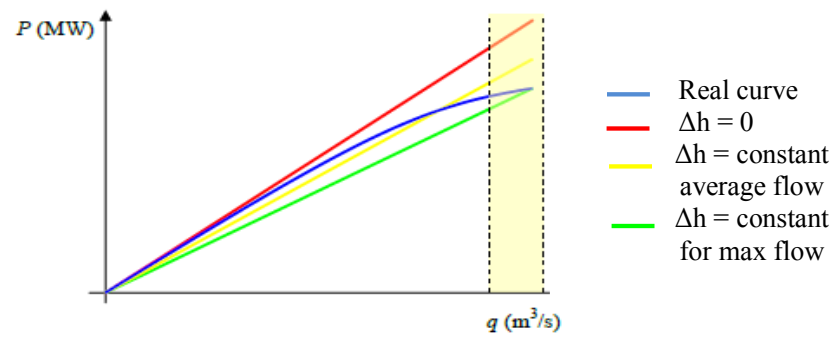

Figure 1. Non linear relation between the power, the flow and the head.

Several approximations have been used to tackle this issue. For instance, the blue curve can be substituted by a linear relation neglecting the head loss term (red curve). In this case the linear red curve is above the real one leading to a poor approximation for larger flows. This is inappropriate because operation decisions tend to use as much water as possible to increase the revenues. Secondly, we could set the head at a fixed value either the average or the maximum. This would lead to the yellow and green curves in Fig. 1. This could be unrealistic for instance for small units or run of river stations in which the head can vary a lot after some hours of operation. If the head loss term is computed for the maximum flow, the error is smaller for large flows and this can be interesting given the trend to operate with as much flow as possible.

In order to avoid these problems, we used the underrelaxed iterative technique detailed in [12] and [13]. This approach solves the non-linear problem using an iterative process in which the value of the net head is successively updated so that in each iteration it is used a refreshed value that is taken as constant along that iteration. Using this strategy has the advantage of turning the HSP to solve in each iteration in a linear optimization problem that can be solved using the Matlab linprog function.

In order to update the value of the head, after solving the HSP in iteration it, the value of the head for unit $i$ in hour $k$ in iteration it +1 is updated using a function $f$ in which the head depends on the volume in the reservoir at the end of iteration it (4). The function relating the head and the volume is known as volume-level curve and the experience shows that just using the volume obtained in iteration it can determine a large change in the head that may originate the divergence of the process. In order to avoid this we used (4) to update the value of the head $h_{i k}$ from iteration it to it +1 . In this expression the argument of the function $f$ includes not only the volume $v_{i k}{ }^{i t}$ obtained at the end of iteration it but also the volume $v_{\text {ik }}$ at iteration it-1.This expression also uses a parameter $\alpha>0$ that has to be adjusted for the hydro system under analysis [13].

$$
h_{i k}{ }^{i t+l}=\mathrm{f}\left(\mathrm{v}_{\mathrm{ik}}{ }^{\mathrm{it}}\right)=\mathrm{f}\left(\mathrm{v}_{\mathrm{ik}}{ }^{\mathrm{it}}+\alpha\left(\mathrm{v}_{\mathrm{ik}}{ }^{\mathrm{it}-1}-\mathrm{v}_{\mathrm{ik}}{ }^{\mathrm{it}}\right)\right)
$$

The HSP objective function is given by (5) for an hydro system with I units and for a planning period with $\mathrm{K}$ sub periods usually of 1 hour each. This problem maximizes the revenue obtained by the generation company along the $\mathrm{K}$ subperiods as a result of selling the generated electricity $P_{\text {Gik }}$ in period k at the price $\pi_{\mathrm{k}}$ subtracted from the amount paid to buy electricity to pump, $P_{P i k}$. The third term in (5) penalizes spilling given by $s_{i k}$ using a coefficient $p s$ set at a value much larger that the electricity prices $\pi_{\mathrm{k}}$. 
$\max \quad Z=\sum_{i=1}^{I} \sum_{k=1}^{K}\left(\pi_{k} \times P_{G i k}\right)-\left(\pi_{k} \times P_{P i k}\right)-\left(p s \times s_{i k}\right)$

Subject to:

$$
\begin{aligned}
& v_{i k}=v_{i(k-1)}+a_{i k}-q_{i k}-s_{i k}+q p_{i k}+ \\
& \sum_{m \subset M_{i}}^{L} q_{m\left(k-\phi_{m}\right)}+s_{m}\left(k-\lambda_{m}\right)-q p_{m}\left(k-w_{m}\right) \\
& v_{i k} \min _{i k} \leq v_{i k} \max \\
& n a_{i k} \min \leq n a_{i k} \leq n a_{i k} \max \\
& q_{i k}^{\min } \leq q_{i k} \leq \min \left(q_{i k}^{\max }, q n_{i} \times \sqrt{\frac{h_{i k}}{h n_{i}}}\right) \\
& q p_{i k}^{\min } \leq q p_{i k} \leq \min \left(q p_{i k}^{\max }, q p n_{i}-\delta_{i} \times\left(h_{i k}-h n_{P i}\right)\right) \\
& 0 \leq s_{i k} \leq \infty \\
& v_{i K}=v_{i K}^{\text {final }} \\
& \operatorname{vol}_{i}{ }^{\min } \leq q_{i k}+s_{i k}-q p_{i k} \leq v_{\text {ol }}{ }_{i}^{\max }
\end{aligned}
$$

In this formulation:

I - total number of hydro plants;

$\mathrm{K}$ - total number of periods;

$\pi_{\mathrm{k}}$ - market price in hour $\mathrm{k}$;

$\mathrm{P}_{\text {Gik }}$ - generation power of unit $\mathrm{k}$, in hour $\mathrm{i}$, in $\mathrm{MW}$;

$\mathrm{P}_{\text {Pik }}$ - pumping power of unit $\mathrm{k}$, in hour $\mathrm{i}$, in $\mathrm{MW}$;

$\mathrm{p}_{\mathrm{s}}$ - penalty factor for spills;

$\mathrm{s}_{\mathrm{ik}}$ - spill of reservoir $\mathrm{i}$, in hour $\mathrm{k}$;

$\mathrm{L}$ - number of upstream reservoirs;

$\mathrm{v}_{\mathrm{ik}}$ - volume of reservoir $\mathrm{i}$, in hour $\mathrm{k}$;

$\mathrm{a}_{\mathrm{ik}}$ - inflow of reservoir $\mathrm{i}$, in hour $\mathrm{k}$;

$\mathrm{na}_{\mathrm{ik}}$ - storage level of reservoir $\mathrm{i}$, in hour $\mathrm{k}$;

$\mathrm{q}_{\mathrm{ik}}$ - discharge volume of reservoir $\mathrm{i}$, in hour $\mathrm{k}$;

qPik - pumping volume of reservoir $\mathrm{i}$, in hour k;

$\mathrm{M}_{\mathrm{i}}$ - set of upstream reservoirs of reservoir $\mathrm{i}$;

$\varphi_{\mathrm{m}}$ - delay of turbine discharge volumes;

$\lambda_{\mathrm{m}}$ - delay of spill volumes;

$\omega_{\mathrm{m}}$ - delay of pumping volumes;

$\mathrm{vol}_{\mathrm{i}}^{\mathrm{min}} / \mathrm{vol}_{\mathrm{i}}^{\mathrm{max}}-\min / \mathrm{max}$ launch volume of reservoir $\mathrm{i}$;

$v_{i}{ }^{\min } / v_{i} \max -\min / \max$ volume limit of reservoir $i$;

$\mathrm{q}_{\mathrm{i}}^{\mathrm{min}}$ - turbine minimum discharge limit of reservoir $\mathrm{i}$;

$\mathrm{q}_{\mathrm{i}}^{\max }$ - turbine maximum discharge limit of reservoir $i$;

$\mathrm{qp}_{\mathrm{i}}^{\mathrm{min}}$ - turbine minimum pumping limit of reservoir $\mathrm{i}$;

$\mathrm{qp}_{\mathrm{i}}{ }^{\max }$ - turbine maximum pumping limit of reservoir $\mathrm{i}$;

$\mathrm{qn}_{\mathrm{i}}$ - nominal turbine discharge volume of reservoir $\mathrm{i}$;

$\mathrm{qpn}_{\mathrm{i}}$ - nominal turbine pumping volume of reservoir $\mathrm{i}$;

$\mathrm{hn}_{\mathrm{i}}$ - nominal turbine head of reservoir $\mathrm{i}$;

$\mathrm{hn}_{\mathrm{Pi}}$ - nominal pumping head of reservoir $\mathrm{i}$;

$\mathrm{h}_{\mathrm{ik}}$ - head of reservoir i, in hour k;

$\delta_{\mathrm{i}}$ - pumping coefficient of reservoir $\mathrm{i}$;

$\mathrm{V}_{\mathrm{iK}}{ }^{\text {final }}$ - volume specified for reservoir $\mathrm{i}$ in the last scheduling period, $\mathrm{K}$.

This objective function (5) is subjected to a set of constraints that includes the water balance equation (6) and operational and technical constraints for each unit $\mathrm{i}$ and for each period $\mathrm{k},(7)$ to (13). These equations are established considering the hydro connections between the units as well as the time lag to allow the discharged water from one unit to arrive to next one, inflows and spills. The problem also includes maximum and minimum flow constrains and maximum and minimum generated and pumping power constraints. For each unit it is also established a constraint imposing the volume at the end of the final scheduling period (12). This value can be obtained from medium or long term planning problems to define longer term strategies for the use of the water. This means that in this paper the HSP problem has a short-term nature but it profits from information from medium to long term water management problems.

\section{DEVELOPED SOLUTION APPROACH}

To consider the impact of the schedule of a set of hydro units on market prices we admitted that the generation company has estimates of the buying and selling curves of all other market agents for each hour $\mathrm{k}$ of the planning horizon and we used the MATLAB linprog function to maximize the Social Welfare Function associated with this set of bids for each hour under analysis. The market clearing price for hour $\mathrm{k}$ is obtained using the dual variable of the generation/demand balance equation of this problem.

This procedure gives a set of initial prices that are used to solve the HSP problem detailed in Section II. As a result, we obtain the operation decisions for each hydro and for each hour (operation as generator or as pump or not operating). Using this information, we obtain the total generation and pumping powers for each hour and these values are used to change the selling and buying curves of that hour. This is done shifting to the right the selling curve as much as the generated power and also shifting the buying curve to the right as much as the pumping power. This means including a zero price selling bid with an amount equal to the power generated by the hydros and to include a buying bid at the maximum market price with an amount equal to the pumping power in that hour. Once these bids are considered for each hour, the Social Welfare Function is maximized updating the prices that are used to solve the HSP in the next iteration.

The above process corresponds to an outer cycle that in each iteration w calls the HSP detailed in Section II. On its turn, the HSP is itself solved using an iterative process during which the value of the head of each unit is updated as also described in Section II. Fig. 2 presents the flowchart of the prices updating outer cycle. In order to smooth the impact of the operation decisions coming from the HSP problem in the market prices, we used an expression similar to (4) to update the prices. This means that the price in hour $\mathrm{k}$ to be used in the next iteration $\mathrm{w}+1$ of the outer cycle is given by (14).

$$
\pi_{k}^{w+1}=\pi_{k}^{a u x}+\beta\left(\pi_{k}^{w}-\pi_{k}^{a u x}\right)
$$

In this expression and for a given hour $\mathrm{k}$ :

$\pi_{k}{ }^{w+1}$ - market price in iteration $\mathrm{w}+1$;

$\pi_{k}{ }^{w}$ - market price used in iteration w of the HSP;

$\pi_{k}^{a u x}$ - market price from the maximization of the Social Welfare Function, using the new selling and buying bids;

$\beta$ - smoothing parameter. 


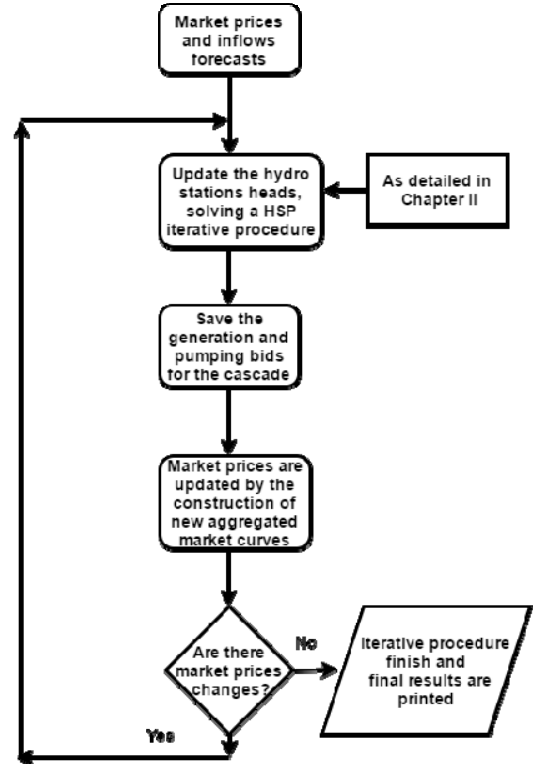

Figure 2. Market prices updating outer cycle.

The outer cycle continues updating the prices and calling the HSP problem to update the operation decisions until a convergence criterium is reached. In this case, the convergence of the external cycle is checked based on the Mean Absolute Percentage Error (MAPE) for the prices in two consecutive iterations, $\mathrm{w}+1$ and $\mathrm{w}$ (15). If the computed MAPE is smaller than a specified limit, then the external iterative cycle stops and the results are displayed.

$$
\text { MAPE }=\frac{1}{K} \frac{\sum_{k=1}^{K}\left|\pi_{k}^{w+1}-\pi_{k}^{w}\right|}{\sum_{k=1}^{K}\left|\pi_{k}^{w+1}\right|}
$$

This work also addressed the fact that the downstream water level of some units can display large elevations when a unit is operating thus reducing the net head. Not considering this effect can originate large errors for smaller or run of river units. To consider this effect, the tailwater of unit $\mathrm{i}$ in hour $\mathrm{k}$ to use in iteration $\mathrm{w}^{+}+1$ of the outer cycle is updated using (16) based on the nominal tailwater of the unit. At the end of iteration $\mathrm{w}$ we compute the variation of the tailwater using (17) that results from the analysis made by EDP Gestão da Produção using measurements for the flows and tailwater levels for the units in the Douro river cascade. This expression indicates that the tailwater level can be elevated at the maximum of $15 \%$ regarding the nominal value, namely when the flow reaches its maximum. The computed tailwater level is then used to reduce the net head thus implying a reduction of the generated power. For a different hydro system or if particular hydro conditions exist for a specific unit, measured values for the flows and tailwater levels should be used to build the most adequate expression to model this effect.

$$
\begin{gathered}
\text { tailwater }_{i k}{ }^{w+1}=\text { tailwater }_{i}^{\text {nom }}+\Delta \text { tailwater }_{i k}{ }^{w+1} \\
\text { Atailwater }_{i k}{ }^{w+1}=0.15 \times\left(q_{\text {Gik }^{w}}{ }^{w} / \text { qmax }_{i}\right) \times \text { tailwater }_{i}^{\text {nom }}
\end{gathered}
$$

In these expressions:

tailwater $_{i}^{\text {nom }}$ - nominal tailwater level of reservoir i; qmax $_{i}$ - maximum flow of reservoir i;

$q_{G i k^{w}}$ - discharge flow of reservoir $\mathrm{i}$ in hour $\mathrm{k}$ in iteration $\mathrm{w}$ of the outer cycle.

Finally, along the iterative process of the outer cycle it is also possible to update the generation and pumping efficiencies used in (1) and (2) since they depend on the flow. This update can be done using information provided by turbine manufacturers for each type of turbine indicating in a graphical way the dependency of these efficiencies on the quotient of the discharged flow regarding its maximum value.

\section{Results For the Douro River CASCADE}

The cascade in the Portuguese section of the Douro River has 9 plants according to the scheme in Fig. 3 having a total installed capacity of $1504.8 \mathrm{MW}$. Units B, C, E and H have pumping capacity. Table I includes the most relevant technical data of this hydro system. The market prices used in the simulations were downloaded from the Iberian Market Operator and the inflows were based on historical data provided by EDP - Gestão da Produção, S.A.

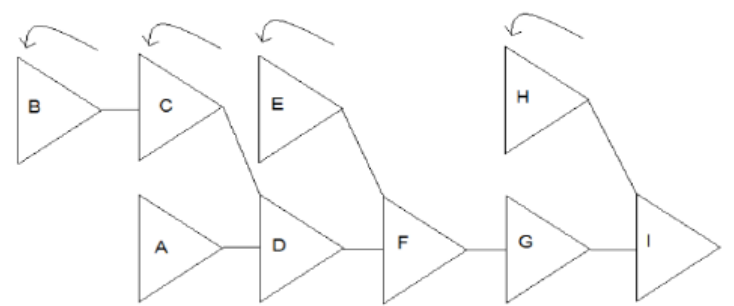

Figure 3. Scheme of the cascade in the Portuguese section of the Douro.

TABLE I

TECHNICAL DATA OF THE HYDRO STATIONS

\begin{tabular}{|lrrrllrl|}
\hline unit & $\begin{array}{r}\mathrm{h}_{\mathrm{n}} \\
\mathrm{m}\end{array}$ & $\begin{array}{c}\mathrm{q}_{\mathrm{G}} \\
\mathrm{m}^{3} / \mathrm{s}\end{array}$ & $\begin{array}{l}\mathrm{q}_{\mathrm{P}} \\
\mathrm{m}^{3} / \mathrm{s}\end{array}$ & $\begin{array}{l}\mathrm{P}_{\mathrm{G}} \\
\mathrm{MW}\end{array}$ & $\eta G$ & $\mu P$ & type \\
\hline $\mathrm{A}$ & 20.5 & 1077 & -- & 186 & 0.90 & -- & Kaplan \\
$\mathrm{B}$ & 94.0 & 170 & 135 & 140 & 0.89 & 0.91 & Francis \\
$\mathrm{C}$ & 30.0 & 120 & 85 & 30.8 & 0.89 & 0.91 & Francis \\
$\mathrm{D}$ & 30.5 & 900 & -- & 240 & 0.92 & -- & Kaplan \\
$\mathrm{E}$ & 93.6 & 310 & 238 & 270 & 0.89 & 0.92 & Francis \\
$\mathrm{F}$ & 27.0 & 744 & -- & 180 & 0.93 & -- & Kaplan \\
$\mathrm{G}$ & 33.3 & 705 & -- & 201 & 0.91 & -- & Kaplan \\
$\mathrm{H}$ & 51.5 & 320 & 279 & 140 & 0.89 & 0.92 & Francis \\
$\mathrm{I}$ & 10.6 & 1350 & -- & 117 & 0.86 & -- & Kaplan \\
\hline
\end{tabular}

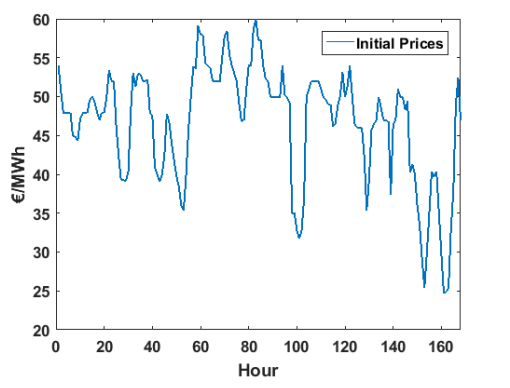

Figure 4. Set of initial market prices.

Fig. 4 presents the market prices profile used for the simulated 168 hours that constitute the period of analysis. The used price scenario presents an average value of 46.65 $€ / \mathrm{MWh}$, with a prices standard deviation of $7.38 € / \mathrm{MWh}$. The initial market prices considered in this paper were based on 
real data downloaded from the OMIE, the Spanish Operator for the Iberian Electricity Market. To allow measuring more accurately the impact of the operation decision in the Iberian electricity market prices, the market prices taken from the OMIE webpage were pre-processed in order to exclude from the real aggregated market curves the units in the Portuguese section of Douro River .

CASE I - In each iteration, the problem to solve is linear. With this approach is possible to solve problems of large dimensions without great computational effort. In this case, the optimization problem involved a total of $2016+1680=$ 3696 decision variables $(4$ hydros $\times 168$ hours $\times 3$ for hydros with pumping plus $5 \times 168 \times 2$ for hydros without pumping) and 10593 constraints ( 9 hydros $\times 168$ hours $\times 7$ technical constraints +9 mandatory final volumes). In first place, the HSP was run using data for a wet week and not considering the impact of the operation decisions on the prices, that is, admitting the hydro units are price takers. This means running the HSP just once, or in an equivalent way, to run just the first iteration of the outer cycle detailed in Section III. The results indicate that generation was correctly positioned in the periods of larger prices and pumping was located in the lower price periods. The total generation was $33803.33 \mathrm{MWh}$, the energy used to pump was $10022.12 \mathrm{MWh}$ and the total revenue was $1506.33 \mathrm{k} €$.

CASE II - Secondly, we ran the HSP for the same wet week as in Case I now considering the impact on prices, that is, the hydro units are price makers, as well as the possibility of adjusting the tailwater levels and the generation and pumping efficiencies. Fig. 5 illustrates the results along the 168 hours of week.

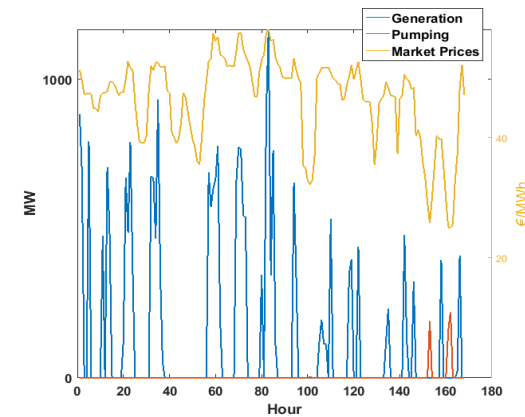

Figure 5. CASE II - Results for the total generated (blue curve) and pumping power (red curve). Final prices in $€ / M W h$ in the yellow curve, right axis.

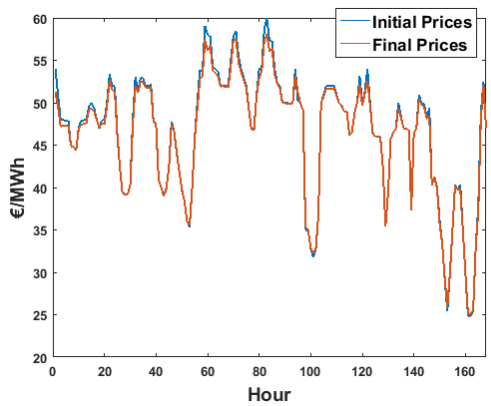

Figure 6. CASE II - Market prices before and after the iterative procedure.

The total generated and consumed energies are 25155.34 and 272.84 MWh and the revenue gets reduced to 1316.73 $k €$. The reduction of the generated energy is explained by the dependency of the generation efficiency and tailwater level on the flow. Additionally, when hydro generation is larger than pumping then the prices tend to reduce due to the new zero price selling bids, as it is indicated by the graphs in Fig. 6. Conversely, when pumping is larger, then prices tend to increase due to the demand increase.

The revenue from selling electricity gets reduced because of the combined reduction of prices and generated electricity. The solution also shows a reduction of pumping to reduce the amount paid to buy electricity (second term in (5)) and to elevate as much as possible the total revenue given by (5).

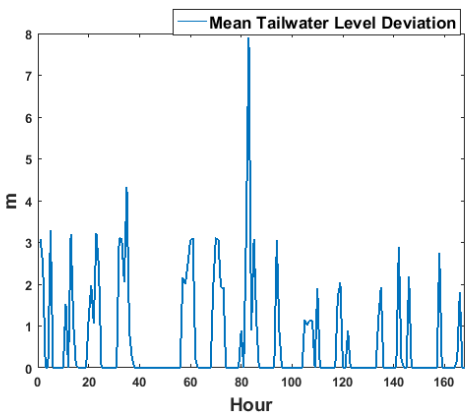

Figure 7. CASE II - Cascade average tailwater level deviation.

Fig. 7 shows that the period with the largest tailwater level deviations regarding the initial levels are coincident with the periods with more generation. However, it is important to notice that the variation of the global mean tailwater level is not directly proportional to the generated power because each hydro station has a different historical mean tailwater level.

The HSP final solution sets the operation of the hydro stations close to their respective maximum discharge flows and efficiencies. Fig. 8 presents the average values along the 168 hours of the week of the discharge efficiencies for the units that are in the generation mode in each hour.

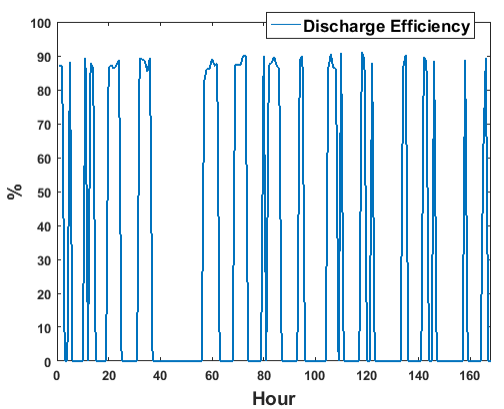

Figure 8. CASE II - Mean discharge efficiency for the cascade (only considering the hydro stations which are generating in each hour).

CASE III - Finally, we considered a dry week limiting the initial available volumes in the units just to $20 \%$ of their maximum value. Fig. 9 shows the generation, the pumping and the electricity prices at the end of the iterative process detailed in Section III. In this case the total revenue drops to $1163.92 \mathrm{k} €$ because there is a reduction of generation due to the reduction of the water availability. Additionally, generation periods are more distributed along time compared with Case II given that this strategy ensures that generation efficiencies are larger. For CASE III, Fig.10 shows the final results for the HSP decision variables. 


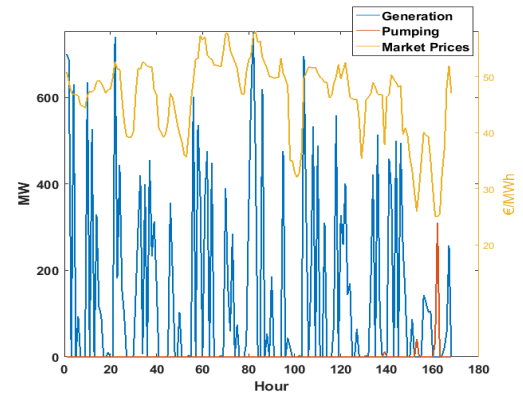

Figure 9. CASE III - Results for the total generated (blue curve) and pumping power (red curve). Prices in $€ / M W h$ in the yellow curve, right axis.

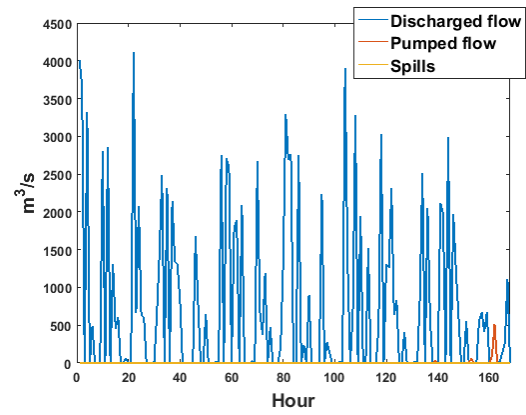

Figure 10. CASE III - Results for the discharged (blue curve), pumped (red curve) and spilled (yellow curve) flows in $\mathrm{m}^{3} / \mathrm{s}$.

\section{CONCLUSIONS}

This paper describes a set of enhancements introduced in the short term HSP problem to consider hydro stations as price makers and the impact of variations of the tailwater and of the efficiency of the hydro circuit in order to obtain a more realistic model. As an example, when going from Case I (hydro units as price takers) to Case II (hydro units as price makers in a wet week) described in Section IV, the revenue reduces by $12.6 \%$ mainly due to the impact of operation generation and pumping decisions on the prices. This effect gains increased relevance as the installed hydro capacity is larger regarding the total capacity and the pumping capacity increases. These aspects are very relevant in the Iberian Electricity Market where the hydro capacity is close to $25 \%$ of the total. Generation companies can therefore profit from this type of models to get more insight on the operation of hydro units and to take more sounded decisions namely in terms of preparing their selling and buying bids to the market operator.

\section{ACKNOWLEDGMENTS}

The first author thanks EDP Gestão da Produção SA, for their help, support and useful discussions held during the development of this project. This work is financed by the ERDF - European Regional Development Fund through the Operational Prog. for Competitiveness and Internationalisation - COMPETE 2020 within project «POCI01-0145-FEDER-006961», and by National Funds through FCT - Portuguese Foundation for Science and Technology as part of project UID/EEA/50014/2013.

\section{REFERENCES}

[1] García-González, J., Parrilla, E., Mateo, A. and Moraga, R., "Building optimal generation bids of a hydro chain in the day-ahead electricity market under price uncertainty", in Proc. 9th Int. Conf. on Probabilistic Methods Applied to Power Systems, Stockholm, Sweden, June 2006.

[2] Sousa, J, C. and Saraiva, J. T., "Simulation of the operation of hydro plants in an electricity market using agent based models", in Proc. $13^{\text {th }}$ IEEE International Conference on the European Energy Market, EEM 2016, Porto, Portugal, June 2016.

[3] Catalão, J., Mariano, S., Mendes, V. and Ferreira, L., "Nonlinear optimization method for short term hydro scheduling considering headdependency", European Transactions on Electrical Power, vol. 20, no. 2, pp. 172-183, 2010.

[4] Catalão, J. P., Mariano, S., Mendes, V. and Ferreira, L. M., "Scheduling of head-sensitive cascaded hydro systems - a non-linear approach", IEEE Trans. on Power Systems, vol. 24, no. 1, pp. 337 - 346, Feb. 2009.

[5] Orero, S. O. and Irving, M. R., "A genetic algorithm modelling framework and solution technique for short term optimal hydrothermal scheduling", IEEE Trans. on Power Systems, vol 13, no. 2, pp. 501 $518,1998$.

[6] Guerreiro, C.A., Saraiva, J. T., Sousa, J. C., Mendes, V. T., "Operation planning of hydro stations using genetic algorithms considering their impact on the electricity market prices", Proc. 11th International European Electricity Market Conference, EEM'14, Kracow, May 2014.

[7] Mandal, Kamal K., Basu, M. and Chakraborty, N., "Particle swarm optimization technique based short-term hydrothermal scheduling", Applied Soft Computing vol. 8, no. 4, pp. 1392-1399, 2008.

[8] Xiaohui, Y., Yanbin, Y. and Yongchuan, Z., "A hybrid chaotic genetic algorithm for short-term hydro system scheduling", Mathematics and Computers in Simulation, vol. 59, no. 4, pp.319-327, Elsevier, 2002.

[9] Sampaio, G. S., Sousa, J, C. and Saraiva, J. T., "Optimization of the operation of hydro stations in market environment using genetic algorithms." European Energy Market (EEM), 2013 10th International Conference on the. IEEE, 2013.

[10]Ferrero, R. W., Rivera, J. F., and Shahidehpour, S. M., "A dynamic programming two-stage algorithm for long-term hydrothermal scheduling of multireservoir systems", IEEE Transactions on Power Systems, vol. 14, no. 4, pp. 1534-1540, 1998.

[11]Fleten, S. E. and Wallace, S. W., "Delta-hedging a hydropower plant using stochastic programming", Optimization In The Energy Industry, pp. 507-524, Springer, 2009.

[12] Sousa, J. C., Mendes, V. T. and Saraiva, J. T., "Estimation of the remuneration of hydro plants in a market environment using an iterative under-relaxation approach", in Proc. of the IEEE 2009 Power Tech, Bucharest, June 2009.

[13] García-González, J., Parrilla, E., Barquín, J., Alonso, J., Sàiz-Chicharro, A. and González, A., "Under-relaxed iterative procedure for feasible short-term scheduling of a hydro chain", in Proc. IEEE Bologna Power Tech, vol. 2, 6 pp., June 2003.

\section{BIOGRAPHIES}

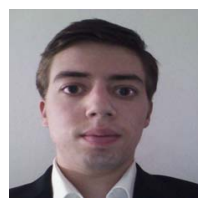

Mário Silva e Castro was born in Amarante, Portugal in 1991 and concluded his MSc degree in July 2016 in the Faculty of Engineering of Universidade do Porto, FEUP. Currently he is with INESC working as researcher on the European project ESGRIDS.

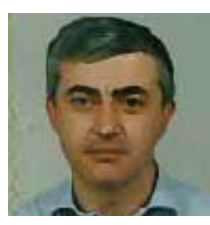

J. T. Saraiva (M'00) got his MSc, PhD, and Agregado degrees in Electrical and Computer Engineering from FEUP in 1987, 1993 and 2002, where he is currently Professor. In 1985 he joined INESC Porto where he is head researcher and collaborated in projects namely in the scope of consultancy contracts with the Portuguese Electricity Regulatory Agency and several utilities.

José Carlos Sousa was born in Porto, Portugal in 1982.

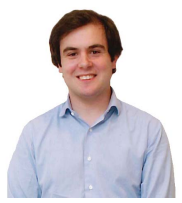

In 2005 and 2007 he got the graduation and the MSc degrees from FEUP where he is currently a $\mathrm{PhD}$ student. Since 2006 he is with EDP Produção in the Regulation and Markets Division having responsibilities on Decision Support and Risk Analyses in Power Systems. 